\title{
Defining Events
}

\author{
Ra-id Abdulla ${ }^{1} \mathbb{C}$
}

Published online: 11 January 2022

(c) The Author(s), under exclusive licence to Springer Science+Business Media, LLC, part of Springer Nature 2021

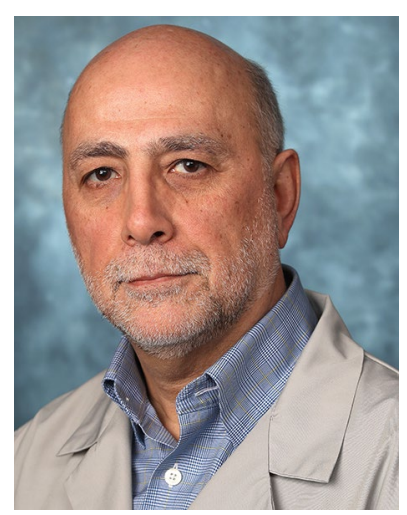

Our lives are studded with defining events shaping our personal history, careers, and the societies we live in. Some of these events are small, while others are massive. The Covid-19 pandemic is certainly one of the life-changing events affecting all those who witnessed it. It was an eye opener! A tiny creature, measuring less than $150 \mathrm{~nm}$, a billionth of a meter, yet causing worldwide havoc for decades to come. I must admit, if you were to ask me two years ago about the Flu Pandemic of the early twentieth century, I would have not been able to describe or imagine the magnitude of death toll it caused, the duration it lasted, or the impact it had on every aspect of life. Now I know better.

It is surprising how knowing something is nothing like living it. Arabs have a saying, "You're better off asking someone who personally experienced a matter, do not bother asking an expert!" The defining events of our lives imprint a deeper change on us. Although they do not change who we are, they can drastically change our perception, and how we reflect on and see things. Furthermore, they provide us with a new direction in life and allow us to reach new destinies.

Ra-id Abdulla

RAbdulla@luriechildrens.org

1 Lurie Children's Hospital, Chicago, USA
As devastating as the pandemic has been, it was not all gloom and doom. Many rose to the challenge and combated it with measures to defeat the viral spread and infection, as well as innovate to modify our daily lives with new ways to continue progress and development. The pandemic impacted most of what we do, but we have not allowed it to prevail or to stop mankind's progress in the various aspects of our lives. Those of us in areas relating to infectious diseases made unbelievable strides toward understanding the nature and behavior of viruses. While others in the medical field, plowed through their work, despite the restrictions and impact of the pandemic, to support our patients and continue research and education. Throughout the pandemic, Pediatric Cardiology experienced a tremendous increase in submissions of scholarly work by scientists who were dedicated to continue advancing our understanding and management of heart diseases in children. The journal was fortunate to include among its editorial rank pediatric cardiologists and congenital cardiovascular surgeons who were equally determined to continue their service to our field and who met the challenge of increasing interest in publication with hard work, again despite the challenges imposed by lockdowns and altered realities.

The past two years was a rollercoaster ride, at times scary and at others thrilling as one faces daunting challenges. These life-changing trials made me think of my own defining events. Three decades ago, when I first became involved in the editorial process of Pediatric Cardiology, it was difficult to imagine that I would continue this effort for this long, it was indeed a blessing. I am most grateful for having had the opportunity to play a small part in the efforts of countless great scientists and clinicians who participated in the functions of this journal. I am delighted by the advances we made in the journal and I am appreciative that I had the opportunity to learn from the pitfalls I committed. Like many functions of our lives, it is reassuring to see this journal, the world of science and the process of medical education continue, if not thrive, despite the oppressing impact of the pandemic. 
It was indeed a privilege to work over the past three decades with all the wonderful professionals at Springer. Their dedication to advancing science and the tenacity with which they cared for their readers is certainly unparalleled!

At the conclusion of my tenure as editor-in-chief, I welcome the leadership of Dr. Karim Diab, the journal's new editor-in-chief, and I look forward to working with him as he advances the journal to new heights.

I pray that we prevail over the challenges we face and that we can attain wisdom as we learn from these experiences.
Wishing all a happy and safe New Year!

Ra-id Abdulla

Senior Editor

Publisher's Note Springer Nature remains neutral with regard to jurisdictional claims in published maps and institutional affiliations. 